\title{
ANÁLISE DA VARIABILIDADE ESPACIAL DO ÍNDICE DE TEMPERATURA E UMIDADE NO RIO GRANDE DO SUL EM DIFERENTES HORÁRIOS
}

\author{
ANALYSIS OF THE SPATIAL VARIABILITY OF THE TEMPERATURE HUMIDITY INDEX \\ IN RIO GRANDE DO SUL AT DIFFERENT TIMES \&
}

ANÁLISIS DE LA VARIABILIDAD ESPACIAL DEL ÍNDICE DE HUMEDAD TEMPERATURA EN RIO GRANDE DO SUL EN DIFERENTES TIEMPOS ${ }^{\circ}$

Recebido em: 25/03/2021 - Aprovado em: 18/08/2021 - Publicado em: 21/09/2021

doi) http://dx.doi.org/10.18011/bioeng2021v15n2p220-234

Zanandra Boff de Oliveira ${ }^{1}$ (zanandraboff@gmail.com)

Alberto Eduardo Knies² (albertoek@gmail.com)

Sidinei Zwick Radons ${ }^{3}$ (sidineiradons@gmail.com)

Eduardo Leonel Bottega ${ }^{1}$ (eduardo.bottega@ufsm.br)

\footnotetext{
${ }^{1}$ Universidade Federal de Santa Maria. Cachoeira do Sul, RS, Brasil.

2 Universidade Estadual do Rio Grande do Sul. Cachoeira do Sul, RS, Brasil.

3 Universidade da Fronteira Sul. Cerro Largo, RS, Brasil.
}

\section{RESUMO}

O presente estudo tem como objetivo analisar a variabilidade espacial do índice de temperatura e umidade (ITU) no RS em diferentes horários do dia. O estudo foi realizado para quarenta e dois municípios. O ITU foi calculado com dados de temperatura e umidade relativa do ar (período de 2000 a 2020). Uma vez detectada a dependência espacial, produziu-se o mapa temático da distribuição espacial do ITU por meio de krigagem ordinária em intervalos de 3 horas $(5-7 ; 8-10 ; 11-13 ; 14-16 ; 17-19 ; 20-22 ; 23-1 ; 2-4$ h). No intervalo entre 8 e 10 h e entre 20 e 22 h, o índice é indicativo de conforto em todo o território; entre 23 e 7 $\mathrm{h}$ há desconforto a estresse por frio $(\mathrm{ITU}<60)$ na maior parte do estado e, entre 11 e $19 \mathrm{~h}$, pode haver algum tipo de desconforto a estresse calórico (ITU>70) em boa parte do RS.

Palavras-chave: Bioclimatologia. Ambiência de Precisão. Geoestatística. Produção animal. Ambiente térmico.

Artigo publicado sob a licença Creative Commons - Atribuição 4.0 Internacional (CC BY 4.0). 


\section{INTRODUÇÃO}

Conhecer a variabilidade espacial de índices de conforto térmico, como o índice de temperatura e umidade (ITU), contribui no estabelecimento de técnicas construtivas e na definição de práticas de acondicionamento térmico ambiental de forma regionalizada.

Banco de dados meteorológicos e informações geográficas (SIG), possibilitam a geração de mapas temáticos, como, por exemplo, o zoneamento bioclimático de uma determinada região, importante para a tomada de decisão com relação à ambiência animal e humana (OLIVEIRA et al., 2006). Para MENDES et al. (2014), o zoneamento bioclimático, por meio do monitoramento das condições climáticas, permite a previsão de áreas com probabilidade de ocorrência do estresse calórico, auxiliando a tomada de decisões quanto ao manejo ambiental, para minimizar o estresse pelo calor. OLIVEIRA et al. (2019), estudando a geoespacialização do ITU no RS para os meses de verão identificaram que $100 \%$ do território está sob desconforto térmico por calor (ITU>74) e que até $27 \%$ do território está sob condições ambientais muito quentes (ITU>79) no mês de janeiro.

Os índices de conforto térmico englobam, em um único parâmetro, o efeito conjunto dos elementos meteorológicos. O ITU conforme BUFFINGTON et al. (1982), integra a umidade relativa e a temperatura do ar. Apesar de existirem índices de conforto térmico mais completos, como o índice de temperatura do globo negro e umidade (ITGU) descrito por BUFFINGTON et al. (1981), que integra os efeitos combinados da temperatura de bulbo seco, da umidade relativa do ar, da radiação solar (Rs) e da movimentação do ar, o ITU tem sido muito utilizado considerar informações meteorológicas normalmente disponíveis em estações meteorológicas e em bancos de dados obtidos a partir de imagens de satélite (OLIVEIRA et al., 2006; OLIVEIRA et al.; 2019).

A combinação entre temperatura e umidade relativa do ar, é a principal condicionante para conforto térmico, pois compromete a manutenção da homeotermia, característica que os animais de produção zootécnica, entre outros, possuem em manter suas temperaturas corporais relativamente constantes, mesmo com as variações da temperatura ambiental, uma função vital alcançada por meio de processos sensíveis e latentes de perda de calor (TINÔCO, 2001; OLIVEIRA et al., 2006).

A magnitude do estresse térmico é influenciada pelo efeito combinado de alta temperatura e umidade relativa do ar, elevada incidência de radiação solar e baixa velocidade do vento, o que reduz a eficiência da perda de calor dos animais para o 
ambiente, situação comum em regiões de clima tropical (DIKMEN; HANSEN, 2009) que pode limitar a produção e a reprodução dos animais (AVENDANO et al., 2006; BAÊTA; SOUZA, 2012). Em locais com clima subtropical, como no Rio Grande do Sul, as condições ambientais são variáveis em função das estações do ano e em um mesmo dia, com elevada amplitude térmica (BURIOL et al., 1973; BURIOL et al., 2015). Os valores de temperatura do ar máxima são até $32,9^{\circ} \mathrm{C}$ e de temperatura mínima de até $5,6^{\circ} \mathrm{C}$ no verão e no inverno, respectivamente (INSTITUTO NACIONAL DE METEOROLOGIA, 2021). Demonstrando os desafios para a ambiência no estado.

Em estudos para a região de Santa Maria - RS BURIOL et al. (2015), verificaram que em termos médios, o desconforto por temperaturas baixas ocorre nas manhãs (9h) de abril a outubro, à noite $(21 \mathrm{~h})$ de maio a setembro e à tarde (15h) de junho a agosto. Enquanto $\mathrm{o}$ desconforto por temperaturas elevadas ocorre à tarde (15h), no mês de janeiro que é o mais quente do ano. Ademais, em função da elevada amplitude térmica diária, as condições de conforto e desconforto térmico se alteram em um mesmo dia, passando de conforto para desconforto e vice-versa. Essa elevada amplitude térmica diária, implica na necessidade de práticas de acondicionamento térmico tanto para frio quanto para calor, bem como no manejo dessas práticas ao longo do dia.

Nesse sentido, o presente trabalho tem como objetivo analisar a variabilidade espacial do ITU no RS em diferentes horários do dia.

\section{MATERIAIS E MÉTODOS}

Os dados meteorológicos horários de temperatura do ar e de umidade relativa do ar, utilizados para o cálculo do ITU, foram obtidos pelo site do Instituto Nacional de Meteorologia (INMET), referentes ao período de 2000 a 2020. Calculou-se o ITU horário médio deste período para quarenta e dois municípios do estado do Rio Grande do Sul, localizados em diferentes regiões (Figura 1). 
Figura 1. Mapa com a localização geográfica dos municípios estudados.

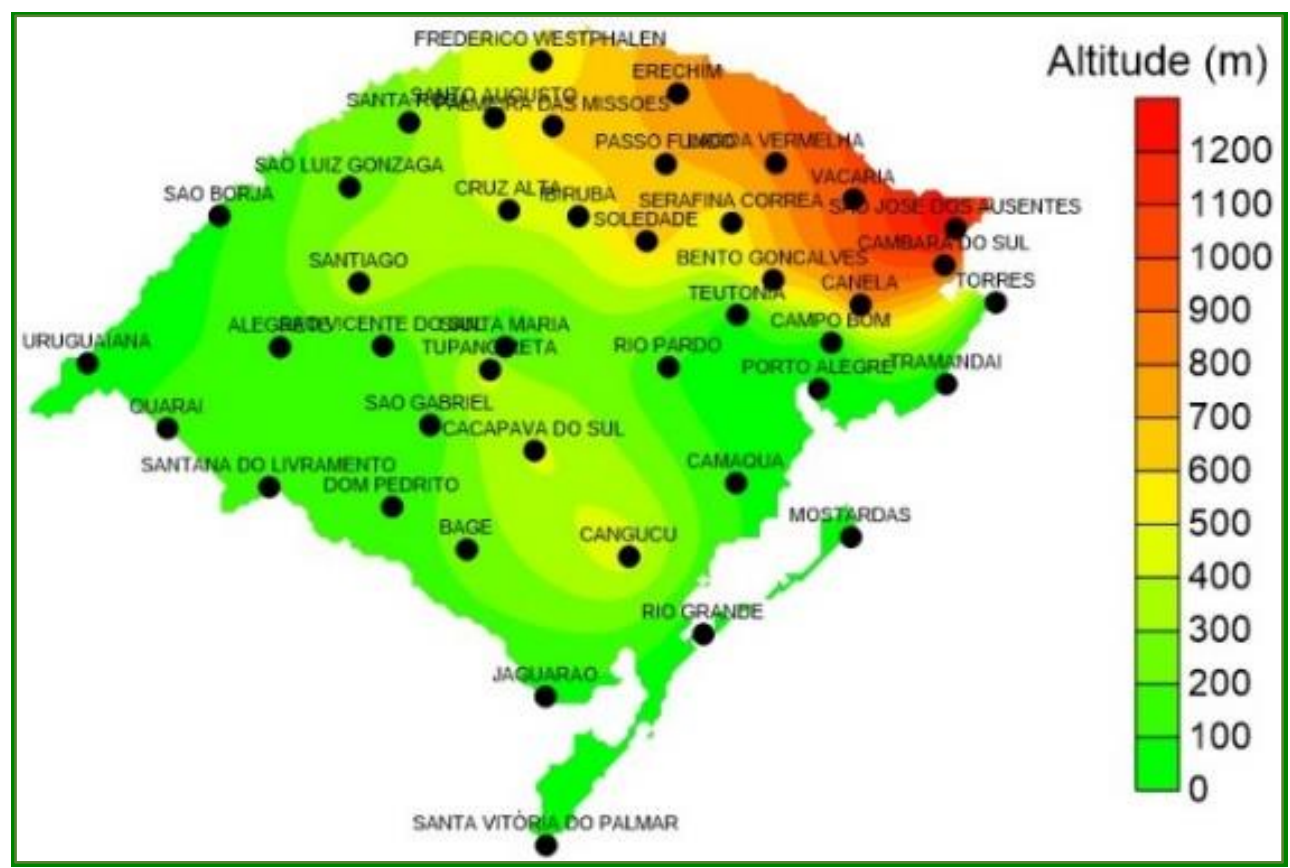

Fonte: Autor, 2021

O ITU foi calculado pela Equação 1, proposta por BUFFINGTON et al. (1982).

ITU $=0,7 \times$ Tar + UR $\times($ Tar-14,3) $/ 100+46,3$

Em que,

ITU: índice de temperatura e umidade, adimensional;

Tar: temperatura de bulbo seco $\left({ }^{\circ} \mathrm{C}\right)$;

UR: umidade relativa do ar (\%).

A dependência espacial do ITU foi avaliada pelos ajustes de variogramas teóricos, pressupondo a estacionaridade da hipótese intrínseca, definida pela Equação 2.

$$
\hat{\gamma}(h)=\frac{1}{2 N(h)} \sum_{i=1}^{N(h)}\left[Z\left(x_{i}\right)-Z\left(x_{i+h}\right)\right]^{2}
$$

Em que,

$\hat{\gamma}(h)$ : Semivariância em função da distância de separação (h) entre pares de pontos;

$h$ : Distância de separação entre pares de pontos, $m$.

$N(h)$ : Número de pares experimentais de observações $Z\left(x_{i}\right)$ e $Z\left(x_{i}+h\right)$ separados por uma distância $\mathrm{h}$.

Foram testados os seguintes modelos: linear com patamar, gaussiano, esférico e exponencial. Selecionou-se o modelo que apresentou a menor soma dos quadrados do 
resíduo (SQR). Após a escolha do modelo, foram determinados os parâmetros: efeito pepita (C0), patamar $(\mathrm{CO}+\mathrm{C})$ e alcance $(\mathrm{A})$. Uma vez detectada a dependência espacial, produziuse o mapa temático de variabilidade espacial do ITU.

Os mapas foram elaborados para intervalos de 3 horas ( 5 às $7 \mathrm{~h}$; 8 às $10 \mathrm{~h}$; 11 às 13 h; 14 às 16 h; 17 às 19 h; 20 às 22 h; 23 à 1 h; 2 às 4 h). A interpolação dos mapas foi realizada utilizando o método da krigagem ordinária. A análise geoestatística e os mapas foram confeccionados com o software GS+.

\section{RESULTADOS E DISCUSSÃO}

Os valores médios de ITU seguem o padrão da temperatura do ar ao longo do dia (Figura 2), sendo mínimo de 53 entre às 5 e 6 h e máximo de 73 entre às 15 e 16 h, em função da disponibilidade de radiação solar na superfície terrestre. Ocorrem variações no horário da ocorrência e nos valores mínimos e máximos ao longo do ano, em função da declinação solar e do movimento terra-sol, que modificam a disponibilidade de energia, com valores máximos no verão e mínimos no inverno.

Figura 2. Análise de box plot (percentis 5, 25, 50, 75 e 95) e médias (vermelho) do ITU observado para os diferentes horários do dia em quarenta e dois municípios do Rio Grande do Sul.

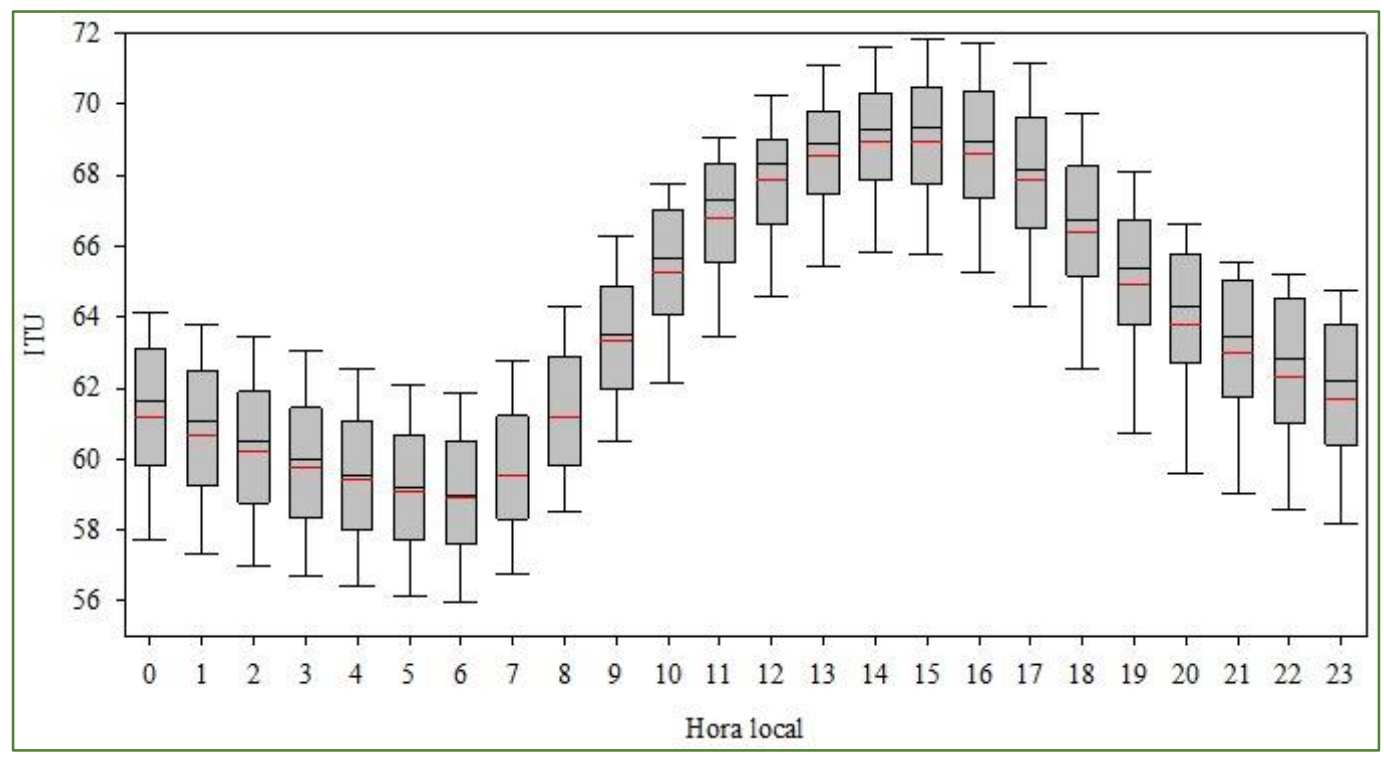

Fonte: Autor, 2021.

A figura 3 apresenta o ITU médio mínimo às 6 e máximo às 15 h para os diferentes locais avaliados no RS. 
Figura 3. Resultado do ITU médio mínimo (6h) e máximo ( 15 h) para os quarenta e dois municípios avaliados no estado do Rio Grande do Sul.

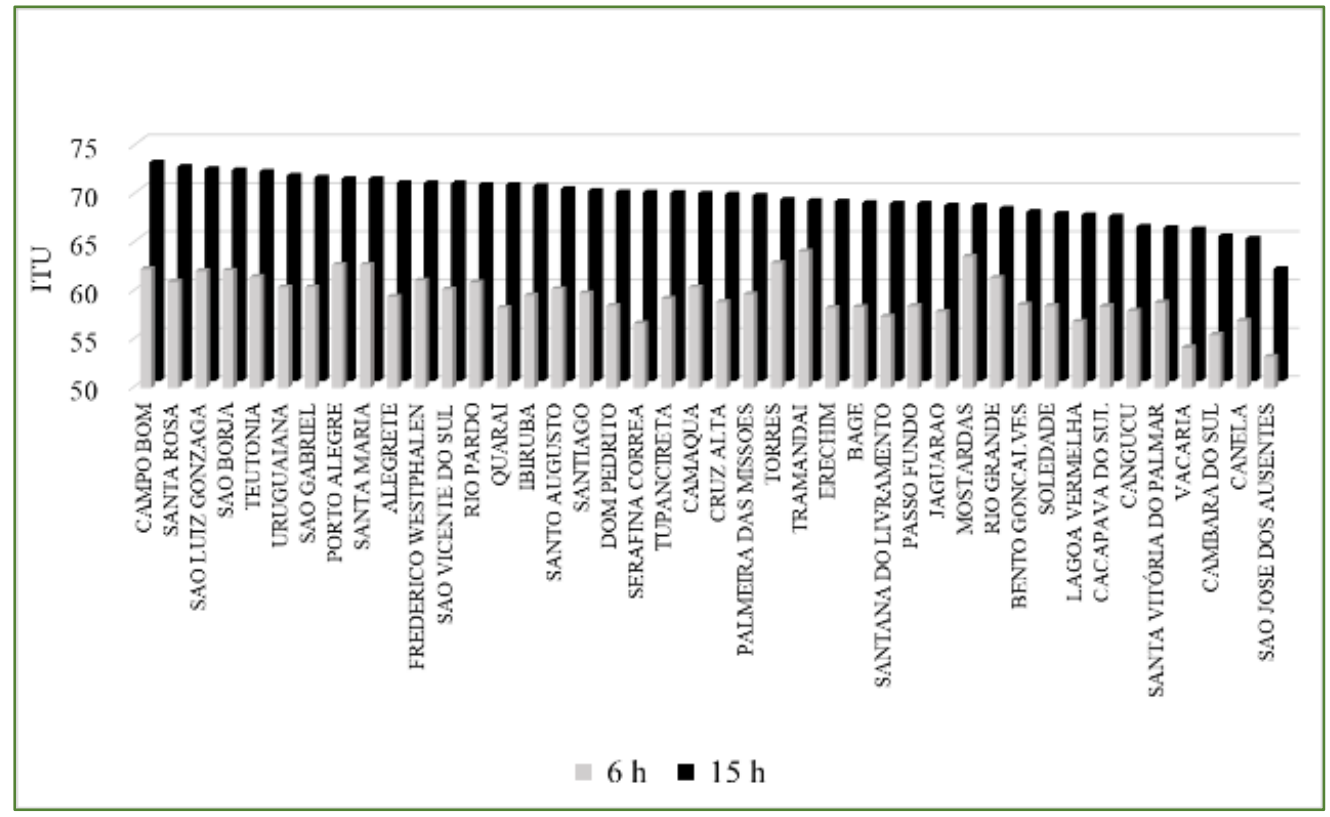

Fonte: Autor, 2021.

Observa-se (Figura 3) que o valor máximo de ITU médio às 6 h é de 64 e às 15 h é 73, em Tramandaí e Campo Bom, respectivamente, ambos na região metropolitana (baixa altitude $<30 \mathrm{~m}$ ). O menor valor do índice para as 6 e 15 h é de 53 e 61, respectivamente, observado em São José dos Ausentes (elevada altitude>1200 m). Corroborando com OLIVEIRA et al. (2020), que afirmam que no estado do RS o ITU apresenta dependência espacial com correlação significativa negativa entre os valores de altitude.

Nas Tabelas 1 e 2 são apresentados, respectivamente, os parâmetros referentes aos ajustes dos semivariogramas e análise de validação cruzada. O ITU apresentou dependência espacial, fato evidenciado pelo ajuste dos modelos teóricos de semivariância apresentados na tabela 1 . 
Tabela 1. Parâmetros dos semivariogramas teóricos referente à modelagem da dependência espacial para os valores do ITU no estado do Rio Grande do Sul, em diferentes horários.

\begin{tabular}{ccccccc}
\hline & \multicolumn{7}{c}{ Parâmetros geoestatísticos } \\
\cline { 2 - 7 } Horário & Modelo & Ao & $\mathbf{C}_{\mathbf{0}}+\mathbf{C}^{(\mathbf{2})}$ & $\mathbf{C}_{\mathbf{0}}^{(\mathbf{3})}$ & $\mathbf{S Q R}^{(4)}$ & $\mathbf{R}^{\mathbf{2 ( 5 )}}$ \\
\hline $5-7 \mathrm{~h}$ & gaussiano & 122,23 & 2,31 & 0,00 & 0,38 & 0,92 \\
\hline $8-10 \mathrm{~h}$ & esférico & 556,71 & 2,95 & 0,57 & 0,09 & 0,95 \\
\hline $11-13 \mathrm{~h}$ & linear & 401,14 & 3,70 & 0,43 & 1,19 & 0,70 \\
\hline $14-16 \mathrm{~h}$ & linear & 401,14 & 3,58 & 0,55 & 1,03 & 0,88 \\
\hline $17-19 \mathrm{~h}$ & exponencial & 311,13 & 5,92 & 0,01 & 2,77 & 0,89 \\
\hline $20-22 \mathrm{~h}$ & gaussiano & 166,68 & 3,26 & 0,73 & 2,16 & 0,84 \\
\hline $23-1 \mathrm{~h}$ & gaussiano & 164,45 & 3,76 & 1,34 & 1,87 & 0,78 \\
\hline $2-4 \mathrm{~h}$ & gaussiano & 113,34 & 2,43 & 0,00 & 0,45 & 0,92
\end{tabular}

Em que: ${ }^{1}$ Alcance $(\mathrm{km}) ;{ }^{2}$ Patamar; ${ }^{3}$ Efeito pepita; ${ }^{4}$ Soma de quadrados do resíduo; ${ }^{5}$ Coeficiente de determinação.

Fonte: Autor, 2021.

Tabela 2. Parâmetros da análise de validação cruzada referente aos modelos teóricos de semivariância ajustados para os valores do ITU no estado do Rio Grande do Sul, em diferentes horários.

\begin{tabular}{|c|c|c|c|c|}
\hline \multirow[t]{2}{*}{ Horário } & \multicolumn{4}{|c|}{ Análise de validação cruzada } \\
\hline & $\mathbf{C R}^{(1)}$ & $\mathbf{Y}^{(2)}$ & $\operatorname{EPP}^{(3)}$ & $\mathbf{R}^{2}$ \\
\hline $5-7 \mathrm{~h}$ & 1,24 & $-14,75$ & 1,01 & 0,62 \\
\hline $8-10 \mathrm{~h}$ & 1,12 & $-8,13$ & 1,06 & 0,61 \\
\hline $11-13 \mathrm{~h}$ & 1,01 & $-1,37$ & 1,04 & 0,74 \\
\hline 14-16 h & 0,99 & 0,12 & 1,22 & 0,60 \\
\hline $17-19 \mathrm{~h}$ & 0,89 & 6,86 & 1,50 & 0,51 \\
\hline $20-22 \mathrm{~h}$ & 0,83 & 10,60 & 1,36 & 0,49 \\
\hline 23-1 h & 1,29 & $-18,37$ & 1,25 & 0,71 \\
\hline $2-4 \mathrm{~h}$ & 1,10 & $-9,88$ & 1,18 & 0,59 \\
\hline
\end{tabular}

Em que: ${ }^{1}$ Coeficiente de regressão; ${ }^{2}$ Intercepto; ${ }^{3}$ Erro padrão de predição.

Fonte: Autor, 2021.

O menor valor de alcance observado foi de $113,34 \mathrm{~km}$ e o maior $556,71 \mathrm{~km}$ (Tabela 1). Quanto maior $o$ alcance, maior a homogeneidade entre as amostras, por isso 0 alcance da dependência espacial é um parâmetro importante para a interpretação dos semivariogramas, pois indica a distância máxima até onde os pontos amostrais estão correlacionados entre si (VIEIRA et al., 2010). Ademais, valores elevados da distância do alcance e da diferença entre efeito pepita e patamar, evidenciado para todos os intervalos de horários estudados, indicam a que o modelo ajustado é estruturado (Tabela 1). $\mathrm{O}$ aspecto estruturado de uma variável regionalizada está vinculado ao comportamento espacial, ou seja, a variabilidade da mesma. Tal comportamento significa que duas amostras vizinhas de ITU estão correlacionadas, ou seja, apresentam uma similaridade entre si. O erro padrão de predição, ou seja, a incerteza associada à estimativa de valores 
em locais não amostrados, variou de 1,01 a 1,50 (Tabela 2), valores aceitáveis de ajuste dos modelos, sendo possível produzir o mapa de variabilidade espacial do ITU no RS para os diferentes horários (Figura 4).

Figura 4. Mapa da variabilidade espacial do ITU médio para o estado do Rio Grande do Sul no seguintes intervalos de horário: a) 23 à 1 ; b) 2 às 4 ; c) 5 às 7 ; d) 8 às 10; e) 11 às 13; f) 14 às 16 ; g) 17 às 19 ; h) 20 às $22 \mathrm{~h}$.

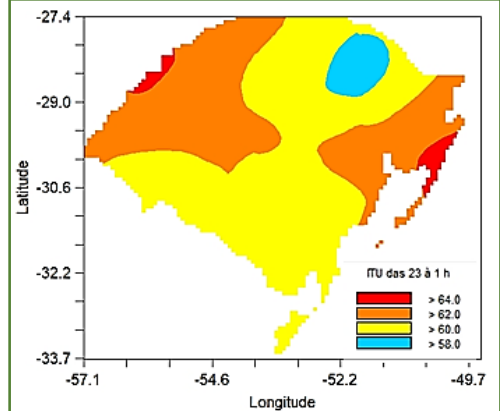

a)

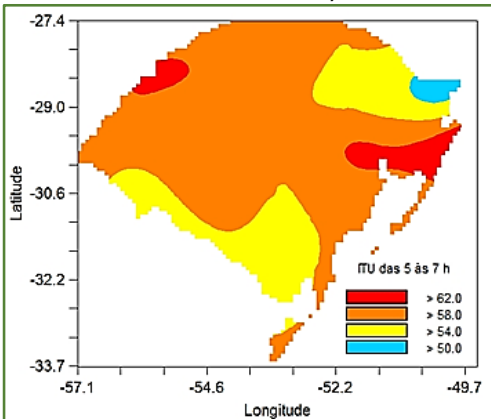

c)

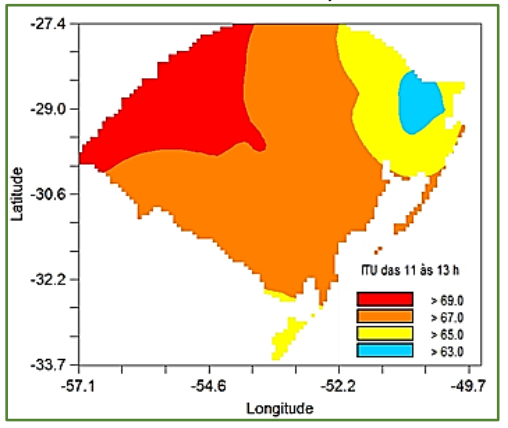

e)

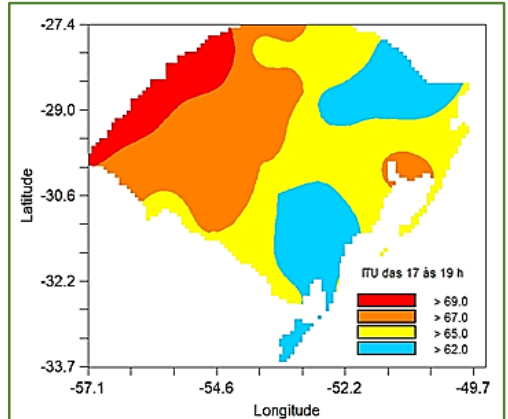

g)

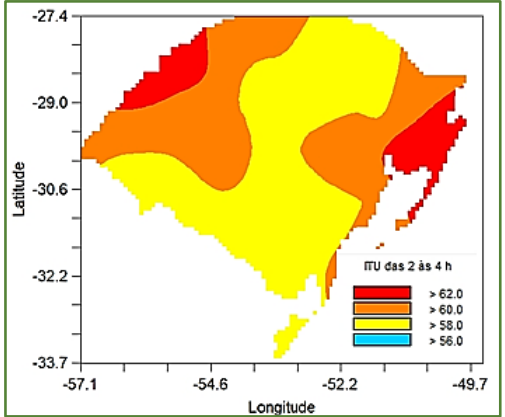

b)

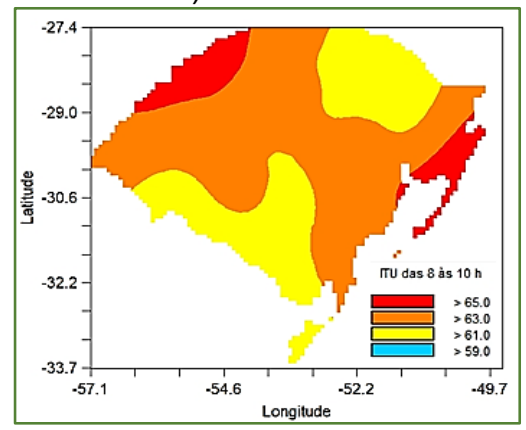

d)
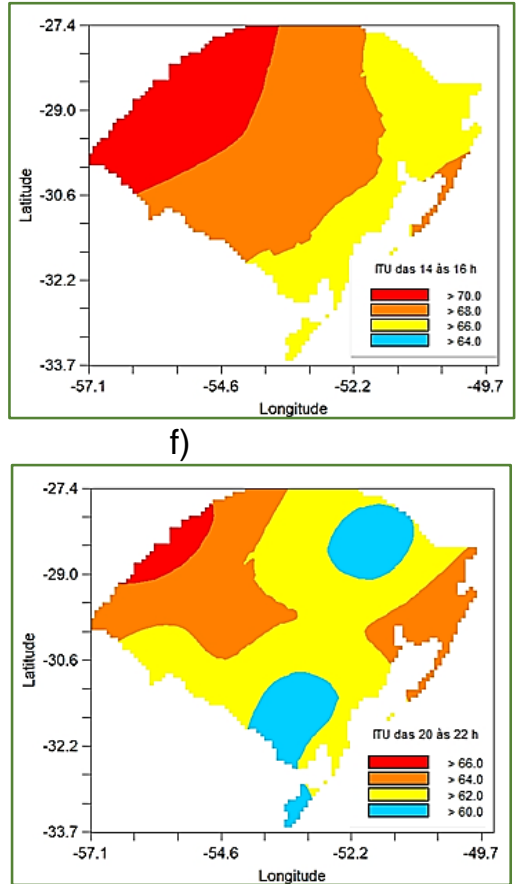

h)

Fonte: Autor, 2021. 
A geoespacialização do ITU no território gaúcho (Figura 4) possibilitou dividir o estado em até quatro classes em função do índice. De um modo geral, a fronteira oeste e região metropolitana/litoral norte, são as que apresentam valores mais elevados do ITU. Enquanto, a região mais ao Sul, divisa com o Uruguai (Jaguarão, Santana do Livramento) e a região de maior altitude (Passo Fundo, Soledade, Lagoa Vermelha, São José dos Ausentes, Canela, Cambará do Sul), apresentam valores mais baixos do índice.

Seguindo a escala do índice de desconforto térmico desenvolvido por ONO; KAWAMURA (1991) para frio, conforme sugere OLIVEIRA; KNIES (2019), pois não há na literatura escala para análise bioclimática do ITU para frio, há desconforto a estresse por frio das 23 às $7 \mathrm{~h}$ (mapas 23 à $1 \mathrm{~h}, 2$ às $4 \mathrm{~h}, 5$ às 7) no locais em azul e amarelo e, no intervalo das 5 às $7 \mathrm{~h}$, na região em laranja também, ou seja, na maior parte do território gaúcho.

Animais de produção sujeitos a condição de desconforto a estresse por frio precisam elevar a produção de calor, que pode ser transferindo para manutenção a energia que seria usada para crescimento ou aumentando o consumo de energia, ambos gerando prejuízos no crescimento dos animais e prejuízos econômicos ao produtor (CASSUCE, 2011; MILLER, 2012; BORTOLANZA et al., 2017).

Assim, modificações ambientais para a redução do frio devem ser adotadas nesses locais e horários. Tais como, fechamento de cortinas em galpões semiabertos, utilização de aquecedores, sobretudo, para animais na fase inicial de vida em confinamento, como frangos e suínos (CASSUCE, 2011; MILLER, 2012; BAÊTA; SOUZA, 2012). Para a produção à pasto, no caso de bezerros, a utilização de abrigos parcialmente fechados contribui para a redução da amplitude térmica e melhora as condições de conforto térmico animal (OLIVEIRA; KNIES, 2021).

No intervalo entre 8 e 10 h $(61<\mathrm{TTU}<67)$ e entre 20 e $22 \mathrm{~h}(60<\mathrm{ITU}<68)$, o índice é indicativo de conforto térmico para humanos e animais de produção em geral (Souza et al. 2010). Cabe salientar que a análise do conforto térmico para animais de produção deve ser minuciosa, respeitando a categoria e a idade destes.

A cor laranja (ITU>67) prevalece na maior parte do território entre 11 e 16 h e, em uma proporção menor entre 17 e 19 h. Nessas áreas e horários, pode ocorrer algum desconforto calórico para animais em uma fase mais avançada do ciclo de produção, como é o caso de frangos de corte a partir da quarta semana de vida (ABREU; ABREU, 2011; SILVA, 2007). 
Já nas regiões em vermelho nos mapas entre 11 e 19 h, práticas de acondicionamento térmico para a redução do calor, como: ventilação natural, ventilação artificial, resfriamento adiabático, exaustão, entre outras, devem ser acionadas. Assim, como em ambiente externo, a disponibilidade de sombreamento natural ou artificial, para a adequação do ambiente às necessidades térmicas dos animais.

Para suínos HANH (1985), considera o valor de ITU até 70 condições de ambiente seguras para o animal, de 71 a 78 é um ambiente crítico. SILVA JUNIOR (2001), descreve que, para vacas leiteiras, ITU menor ou igual a 70 é considerado normal; de 70 a 72 estado de alerta (índice crítico para a produção de leite) e de 72 a 78 estado crítico, no qual há redução na produção de leite.

OLIVEIRA et al. (2020), investigando o conforto térmico de trabalhadores rurais durante a colheita do tabaco na região do vale do Rio Pardo - RS, ressaltam que o estresse calórico que existe em função das condições meteorológicas no turno da tarde pode ser potencializado com estresse físico acumulado ao longo do dia de trabalho. Nesse caso, sugere-se pausas nas atividades.

Os resultados demonstrados nesse estudo são do ITU médio horário. Certamente há uma importante variação nesses valores horários nas diferentes épocas do ano, sobretudo, para mais (verão) e para menos (inverno), que devem ser considerados para o manejo diário das práticas de acondicionamento térmico. Contudo, os resultados aqui apresentados contribuem para o planejamento regional de práticas de modificação ambiental, assim como, para o planejamento do manejo destas práticas e monitoramento de variáveis meteorológicas no ambiente de produção.

\section{CONCLUSÕES}

A geoespacialização do ITU no Rio Grande do Sul permitiu dividir o território em até quatro classes. A fronteira oeste e região metropolitana/litoral norte apresentam valores mais elevados do índice e os menores valores ocorrem na região fronteira com o Uruguai e de maior altitude (parte da Serra e do Planalto).

No intervalo entre 8 e 10 h e entre 20 e 22 h $(60<I T U<68)$, o índice é indicativo de conforto térmico em todo o território gaúcho, entre 23 e $7 \mathrm{~h}$, há desconforto a estresse por frio $(I T U<60)$ na maior parte do estado e, entre 11 e $19 \mathrm{~h}$ pode haver algum tipo desconforto por calor (ITU>67) a estresse calórico (ITU>70) em boa parte do território do RS. 
Assim, para a adequação do ambiente as necessidades térmicas dos animais de produção, práticas de acondicionamento térmico tanto para frio quanto para calor são necessárias no RS, o manejo destas ao longo do dia depende da categoria e idade dos animais.

\section{REFERÊNCIAS}

ABREU, V. M. N.; ABREU, P. G. Os desafios da ambiência sobre os sistemas de aves no Brasil. Revista Brasileira de Zootecnia, v.40, p.1-14, 2011 (supl. especial).

AVENDANO, R. L.; ALVAREZ, V. F. D.; CORREA, C. A.; SAUCEDO, Q. J. S.; ROBINSON, P. H.; FADEL, J. G. Effect of cooling Holstein cows during the dry period on posíparíum performance under heat stress conditions. Livestock Production Science, v.105, p.198-206, 2006.

BAÊTA, F. C.; SOUZA, C. F. Ambiência em edificações rurais: Conforto animal. 2.Ed. 1를 reimpressão, Viçosa: EDUFV, 269p, 2012.

BORTOLANZA, P.J.; MICHELIN, G.P.; ENDO, T.S.; SUELEN, E.; ORTIZ, Q. E.; MARIANA, A.; ALEXANDRA, B. SEBASTIÃO JUNIOR, G. Importância do ambiente térmico em produção de suínos na fase de creche. Revista Electrónica de Veterinaria. v.18, n. 2, febrero, p. 1-11, 2017.

BUFFINGTON, D. E.; COLLIER, R. J.; CANTON, G. H. Shede managemente systems to reduce heat stress for dairy cows. St. Joseph: American Society of Agricultural engineers, p. 16 (PAPER 82-4061), 1982.

BUFFINGTON, D.E.; COLLAZO-AROCHO, A.; CANTON, G.H.; PITT, D.; THATCHER, W.W.; COLLIER, R.J. Black-Globe-Humidity Index (BGHI) as comfort equations for dairy cows. Transactions of the ASAE, St. Joseph, v.24, n.3, p.711-14, 1981.

BURIOL, G. A.; ESTEFANEL, V.; FERREIRA, M.; PINTO, H. S. Estimativa das médias das temperaturas máximas mensais e anuais do Estado do Rio Grande do Sul. Revista do Centro de Ciências Rurais, v.3, p.131-150, 1973.

BURIOL, G.A.; ESTEFANEL, V.; RIGHI, E.Z.; BRESSAN, V.C. Conforto térmico para os seres humanos nas condições de ambiente natural em Santa Maria, RS, Brasil. Ciência Rural, Santa Maria, v.45, n.2, p.223-230, fev, 2015.

CASSUCE, D. C. Determinação das faixas de conforto térmico para frangos de corte de diferentes idades criados no Brasil. 2011. 91 P. Tese (Doutorado em Engenharia Agrícola) - Universidade Federal Rural de Viçosa, Viçosa, 2011.

DIKMEN, S.; HANSEN, P. J. Is the temperature-humidity index the best indicator of heat stress in lactating dairy cows in a subtropical environment? Journal of Dairy Science, v.92, p.109-116, 2009. 
HAHN, G.L. Management and housing of farm animals in hot environments. M. Yousef ed. Stress Physiology in Livestock, CRC Press, Boca Raton v.2, 151-174p,1985.

INSTITUTO NACIONAL DE METEOROLOGIA. Normais Climatológicas do Brasil (Período de 1981-2010). Disponível em: https://portal.inmet.gov.br/normais Acesso em: 17/08/2021.

MENDES, A.M.P; AZEVEDO, M.; LOPES, P.M.O.; Moura, G.B.A. Zoneamento bioclimático para a raça ovina Dorper no Estado de Pernambuco. Pesquisa Agropecuária Brasileira, 49: 986-993, 2014.

MILLER, T. G. Swine Feed Efficiency: Influence of Temperature. lowa Pork Industry Center Fact Sheets, lowa State University: 11: 1-2.2012.

OLIVEIRA, L.M.F.; YANAGI JUNIOR; FERREIRA. E.; CARVALHO, L.G.; SILVA, M.P. Zoneamento bioclimático da região sudeste do Brasil para o conforto térmico animal e humano. Engenharia Agrícola. vol.26 no.3 Jaboticabal Sept./Dec. 2006.

OLIVEIRA, Z.B, BOTTEGA, E.L; OLIVEIRA, M.B; MOARES, C.S; LINK, T.D. Analise do conforto térmico no estado do Rio Grande do Sul utilizando técnicas geosestatísticas e dados das normais climatológicas. Engenharia na Agricultura, v. 27, p. 195-203, 2019.

OLIVEIRA, Z.B.; KNIES, A.E.; BOTTEGA, E.L. Conforto térmico de trabalhadores rurais durante a colheita do tabaco. Brazilian Journal of Biosystems Engineering, v. 14(3) 299-308, 2020.

OLIVEIRA, Z.B.; KNIES, A.E. Conforto térmico em protótipos de bezerreiros na região Central do RS. Brazilian Journal of Development, Curitiba, v.7, n.1, p. 8748-8759 Jan. 2021.

OLIVEIRA, Z.B.; KNIES, A.K. Análise bioclimática e investigação do conforto térmico em ambiente externo na região central do RS. Energia na Agricultura, Botucatu, v. 34, n. 3, p. 377-388, julho-setembro, 2019.

ONO, H. S. P.; KAWAMURA T. Sensible Climates in Monsoon Asia. International Journal Biometeorology. vol. 35, no XX, pp. 39-47, 1991.

SILVA JÚNIOR, J. L. C. Zoneamento da região sudeste do Brasil, utilizando o índice de temperatura e umidade, para o gado leiteiro. Universidade Federal de Viçosa. Tese. Programa de Pós-Graduação Meteorologia Agrícola. 73 pg, 2001.

SILVA, E. T. Índice de temperatura e umidade (ITU) na produção de aves para a Mesoregião do Nordeste e Norte pioneiro Paranaence. Revista Acadêmica, V.5, n.4, p.385,390, 2007.

SILVA, T.G.F.; MOURA, N.S.V; SÁ, I.S.S.; ZOLNIER, S.; TRUCO, S.H.N.; SOUZA, L.S.B. Cenários de mudanças climáticas e seus impactos na produção leiteira em estados nordestinos. Revista Brasileira de Engenharia Agricola e Ambiental-Agriambi. vol.14, n.8, pp.863-870, 2010. 
TINÔCO, I. F. F. Avicultura industrial: novos conceitos de materiais, concepções e técnicas construtivas disponíveis para galpões avícolas brasileiros. Revista Brasileira de Ciência Avícola, Campinas, v.3, n.1, p.1-26, 2001.

VIEIRA, S.R, GUEDES FILHO, O, CHIBA, M.K, MELLIS, E.V., DECHEN, S.C.F. \& DE MARIA, I.C. Variabilidade espacial dos teores foliares de nutrientes e da produtividade da soja em dois anos de cultivo em um Latossolo Vermelho. Revista Brasileira de Ciência do Solo, v. 4, n. 5, 2010. 


\begin{abstract}
This study aims to analyze the spatial variability of the temperature and humidity index (THI) in RS at different times of day. The study was carried out for forty-two municipalities. The THI was calculated using temperature and relative humidity data (period 2000 to 2020). Once the spatial dependence was detected, the thematic map of the spatial distribution of the ITU was produced by means of ordinary kriging at 3-hour intervals $(5-7 ; 8-10 ; 11-13 ; 14$ $16 ; 17-19 ; 20-22 ; 23-1 ; 2-4 \mathrm{~h}$ ). In the interval between 8 and 10 am and between 8 pm and $10 \mathrm{pm}$, the index is indicative of comfort throughout the territory; between 23 and $7 \mathrm{~h}$ there is discomfort due to cold stress $(\mathrm{THI}<60)$ in most of the state and, between 11 and $19 \mathrm{~h}$, there may be some type of discomfort due to heat stress ( $\mathrm{THI}>70$ ) in most of the state of Rio Grande do Sul.
\end{abstract}

Keywords: Bioclimatology. Precision Ambience. Geostatistics. Animal production. Thermal environment.

\title{
RESUMEN
}

Este estudio tiene como objetivo analizar la variabilidad espacial del índice de temperatura y humedad (ITU) en RS en diferentes momentos del día. El estudio se realizó para cuarenta y dos municipios. La ITU se calculó utilizando datos de temperatura y humedad relativa (período 2000 a 2020). Una vez detectada la dependencia espacial, se elaboró el mapa temático de la distribución espacial de la UIT mediante kriging ordinario a intervalos de 3 horas $(5-7 ; 8-10 ; 11-13 ; 14-16 ; 17-19 ; 20-22 ; 23-1 ; 2-4 \mathrm{~h})$. En el intervalo entre las 8 y las 10 de la mañana y entre las 8 de la noche y las 10 de la noche, el índice es indicativo de comodidad en todo el territorio; entre las 23 y las $7 \mathrm{~h}$ hay malestar por estrés por frío (ITU $<60$ ) en la mayor parte del estado y, entre las 11 y las $19 \mathrm{~h}$, puede haber algún tipo de malestar por estrés por calor (ITU> 70) en la mayoría de los casos estado de Rio Grande do Sul.

Palabras-clave: Bioclimatología. Ambiente de precisión. Geoestadística. Producción animal. Entorno termal. 


\section{LICENÇA DE USO}

Este é um artigo publicado em acesso aberto (Open Access) sob a licença Creative Commons Atribuição 4.0 Internacional (CC BY 4.0), que permite uso, distribuição e reprodução em qualquer meio, desde que o trabalho original seja corretamente citado. Mais informações em: http://creativecommons.org/licenses/by/4.0

\section{CONFLITO DE INTERESSES}

Os autores declaram que não há conflito de interesses neste trabalho.

\section{CONTRIBUIÇÕES AUTORAIS}

Autor 1: Autor principal do trabalho.

Autor 2: Responsável pela coautoria do trabalho.

Autor 3: Responsável pela coautoria do trabalho.

Autor 4: Responsável pela coautoria do trabalho.

\section{AGRADECIMENTO}

Ao INMET pela disponibilização dos dados meteorológicos.

\section{COMO REFERENCIAR}

OLIVEIRA, Zanandra Boff de; KNIES, Alberto Eduardo; RADONS, Sidinei Zwick; BOTTEGA, Eduardo Leonel. Análise da variabilidade espacial do índice de temperatura e umidade no Rio Grande do Sul em diferentes horários. Revista Brasileira de Engenharia de Biossistemas (Tupã), v. 15, n. 2, p. 220-234, 2021. DOI: http://dx.doi.org/10.18011/bioeng2021v15n2p220-234.

\section{RESPONSABILIBADE EDITORIAL}

Prof. Dr. Fernando Ferrari Putti ${ }^{1}$, Prof. Dr. Paulo Sérgio Barbosa dos Santos ${ }^{1}$, Prof. Dr. Eduardo Festozo Vicente ${ }^{1}$ e Prof. Dr. Diogo de Lucca Sartori ${ }^{1}$

${ }^{1}$ Universidade Estadual Paulista "Júlio de Mesquita Filho", FCE - Faculdade de Ciências e Engenharia, Tupã, SP, Brasil. 